\title{
Cluster Analysis of Geomagnetic Disturbances Impact on Reliability of Microprocessor Protection
}

\author{
Platonova Elena Vladimirovna, \\ Khakass Technical Institute - Branch of Siberian Federal \\ University \\ Abakan, Russia \\ eplatonova@yandex.ru
}

\author{
Chistyakov Gennady Nikolaevich \\ Khakass Technical Institute - Branch of Siberian Federal \\ University \\ Abakan, Russia \\ Chist2@yandex.ru
}

\begin{abstract}
In the secondary circuits of power system facilities geomagnetic variations cause geoinduced current which is, according to the nature of its influence, a conducted electromagnetic disturbance; so, it can result in the incorrect operation of microprocessor protection relays. The geoinduced current values are determined by the intensity and duration of variations of the geomagnetic power and angle components. The fuzzy cluster analysis was carried out to define influence of geomagnetic variations on the operation of microprocessor protection relays maintained in the power system facilities of the Republic of Khakassia. The authors also define time and amplitude intervals of the variation rate for geomagnetic power and angle components, which cause incorrect operation of microprocessor protection relays. The results of the fuzzy clustering show proper coincidence with the results obtained with numerical differentiation of functions in a tabular form, with the construction of Lagrange interpolation polynomials of the second order. The analysis outcomes are important for the prediction and prevention of possible incorrect operation of microprocessor protection relays at the power system facilities during geomagnetic storms.
\end{abstract}

Keywords- microprocessor protection relays; geomagnetic variations; fuzzy cluster analysis

\section{INTRODUCTION}

For the last ten years, space weather has been a focus of the scientific interest not only on the part of physicists, astronomers or physicians, but also on the part of technical specialists involved into the power system management. Works $[1,2,3,4,5,6,7,8]$ say that space weather disturbances can have a significant impact on the reliable operation of electric power systems with high-voltage long-distance transmission circuits and substations. Magnetospheric and ionospheric electric current creates ground-level geomagnetic variations that cause a sort of quasipermanent geoinduced current in the long closed-loop grounded conductive systems. In the power supply systems this current flows through the grounded neutrals of high voltage winding of power transformers $[9,10$, $11,12,13,14]$ maintained at higher voltage substations. The geoinduced current flow through the grounded windings causes significant heating of metal and current-carrying parts of the power transformer, which turns off the transformer and disrupts the electricity supply to the consumers.
Works $[5,10,15]$ consider the cases of geoinduced current as conductive electromagnetic disturbances. Contemporary microprocessor devices of relay protection and automatics (MDRP) maintained at power substations for the purpose of protecting from emergency and unfavorable modes of operation are especially sensitive to the disturbances $[16,17$, 18]. Electromagnetic disturbances are a cause of MDRP incorrect operation, which can bring technological disturbances and turn-off of the vital power system facilities [19].

Thus, the reliability monitoring for the contemporary electric power systems puts forward a number of tasks: to research the nature of the geoinduced current influence on the power system operation; to reveal regularities showing when geoinduced current occurs in electric power system facilities and to develop engineering approaches and software to predict possible technological disturbances at the electric power system facilities due to geomagnetic variations.

\section{TARGET AND METHOD OF RESEARCH}

The geomagnetic influence on MDRP incorrect operation was investigated in the context of the power system facilities of the Republic of Khakassia. The research was carried out with the support of the regional grant from RFBR and the Republic of Khakassia № 16-48-190141 - "Study of Power Supply Reliability in the Republic of Khakassia in the Period of Geomagnetic Storms".

The power system of the Republic of Khakassia is geographically located within $53 \div 54$ degrees of northern latitude to include complex electric networks of $110 \div 500 \mathrm{kV}$, with a large number of long-distance transmission circuits.

The researchers analyzed technological disturbances in the power system of the Republic of Khakassia for the period of four years. The research refers to the information for the period from 2013 to 2016, provided by the branch of JSC "SO UPS" "Regional Dispatch Department of the Power System of the Republic of Khakassia". If compared to the total technological irregularities, the technological disturbances percentage caused by the incorrect operation of MDRP at the power system facilities was $2.11 \%$ in $2013,3.97 \%$ in $2014,8.56 \%$ in 2015 and $7 \%$ in 2016. The analyzed technological disturbances occurred under favorable weather conditions, without any 
obvious reasons, but in most cases they were accompanied by geomagnetic storms of various intensity.

It was supposed that a certain fraction of the MDRP incorrect operations could be caused by geomagnetic variations. Rate variations for geomagnetic power and angle components were determined by calculation, particularly, with numerical differentiation of functions in a tabular form, with the construction of Lagrange interpolation polynomials of the second order.

To study the influence of geomagnetic variations on the MDRP operation there were used geomagnetic field characteristics published in the web-site of Pushkov Institute of Earth Magnetism, Ionosphere and Radio Waves of the Russian Academy of Sciences, fixed by Moscow and Irkutsk observatories [20]. The full vector of geomagnetic tension $H_{t}$ was considered with power components $H, X, Y$ and $Z$ and magnetic variation $D$.

Previous papers [21, 22] showed that all the considered cases of MDRP incorrect operation synchronized with intensive and continuous variations of geomagnetic components. The complexity of the analysis is that the statistics concerning the geomagnetic variations is characterized by fuzzy and uncertain links and interactions. The conclusions presented in $[21,22]$ are of an expert nature, being not analytical. In order to confirm or refute these conclusions, we suggested applying a fuzzy cluster analysis of MDRP incorrect operations. The fuzzy clustering was performed with $\mathrm{R}$ program.

Using the fuzzy clustering in $\mathrm{R}$ program, we can form groups (clusters) of the similar numerical characteristics of the geomagnetic field. The results of clustering will be interpreted as manifestation of the influence of some factor that is associated with the analyzed data. Due to the similarity of the properties the detailed study of this influence will reveal regularities necessary for understanding when monitoring the geomagnetic impact on MDRP incorrect operations.

\section{ANALYSIS OF GEOMAGNETIC VARIATIONS DURING GEOMAGNETIC STORMS}

We have analyzed all the technological disturbances in the power system caused by MDRP incorrect operations for the period from 2013 to 2016 . The results of the analysis allowed formulating the conditions when the geomagnetic field affects MDRP operation.

Below is the analysis of one case of MDRP incorrect operation in the power system of the Republic of Khakassia, which took place at 02:08 on July 22, 2013. It should be noted that in July 2013 the geomagnetic field was characterized by a high background and frequent disturbances throughout the month. During this month the power system suffered 36 technological disturbances (the highest record for the period from 2013 to 2016), two of them (including the technological disturbance of July 22, 2013) were caused by MDRP incorrect operation.
To perform clustering, there were selected statistical values $H, Z, D$ and calculated values of their variations $d H / d t, d Z / d t$ and $d D / d t$ in the four-hour interval from 00:10 to 04:10.

The results of the complex fuzzy clustering are shown in Figure 1. Values $H, Z, D$ in relative units (ratio of the maximum) are fixed on the abscissa axis. Values $d H / d t, d Z / d t$ and $d D / d t$ in relative units are on the ordinate axis. The characteristics of $d D / d t=f(D)$ are indicated green, the characteristics of $d H / d t=f(H)$ are blue, the characteristics of $d Z / d t=f(Z)$ are grey.

\section{$H, Z, D$, p.u.}

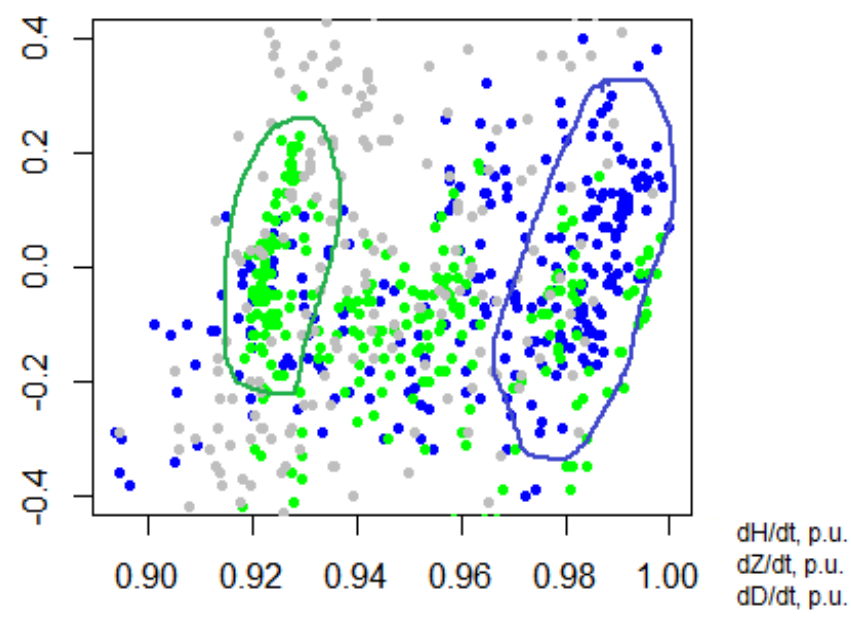

Fig. 1. Graphical presentation of the results of the complex cluster analysis based on the data of 22.07.2013

Figure 1 show that $H$ component cluster is more expressed in the selected four-hour interval at the level of $97 \div 99$ percent of the component maximum. Continuous and intensive variations of $d H / d t$ occur in the range of \pm 35 percent of the maximum, with the sign change of $d H / d t$. The rate of change with $H$ is increasing at the positive $d H / d t$ (field "acceleration"), while the negative $d H / d t$ makes the change rate decrease (field "braking").

D component also allows designating a cluster where more or less continuous variations of $d D / d t$ occur in the range of \pm 20 percent of the maximum, with the sign change of $d D / d t$. The variations correspond to $D$ values at $92 \div 93$ percent of the maximum. $Z$ component cluster is practically not visible, although $d Z / d t$ values are in the range of 80 percent, with the sign change of $d Z / d t$. It means that at such varied values of $Z$ and $d Z / d t$, we cannot consider $Z$ component variations continuous.

According to Figure 1, it is possible to assume that the geoinduced current that allegedly contributed to MDRP incorrect operation on July 22, 2013 was caused by $d H / d t$ variations.

The complex clustering gave us a total vision of the geomagnetic variations. The variation nature of any single field component can be identified by clustering according to one 
parameter and by making the regression line. The results of such clustering for MDRP incorrect operation on July 22, 2013 are presented in Figures 2, 3, 4. The abscissa axis shows the components values in nanotesla, while the ordinate axis showing the derivatives values in nanotesla per minute.

\section{$\mathrm{H}$, nanoTesla}

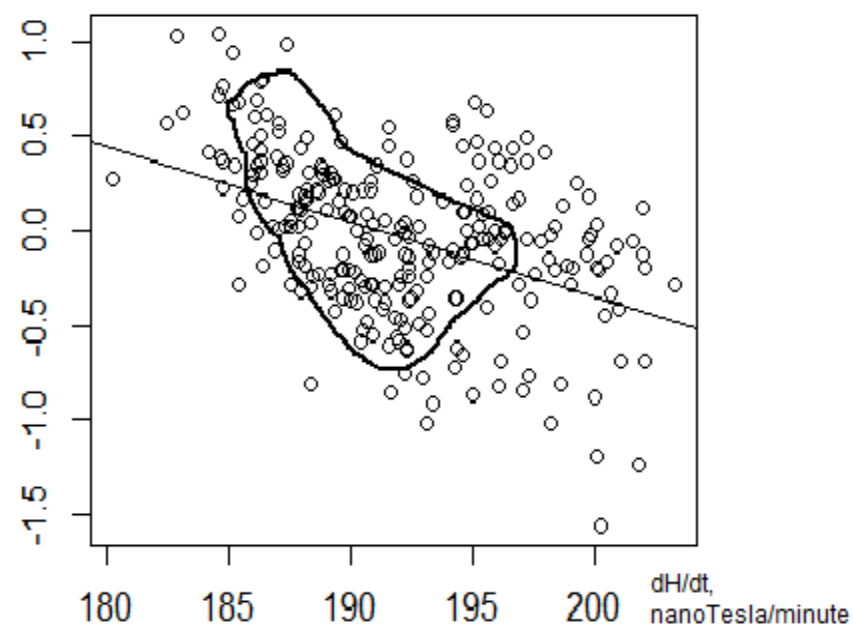

Fig. 2. Graphical representation of the cluster analysis results with $H$ component, 22.07.2013

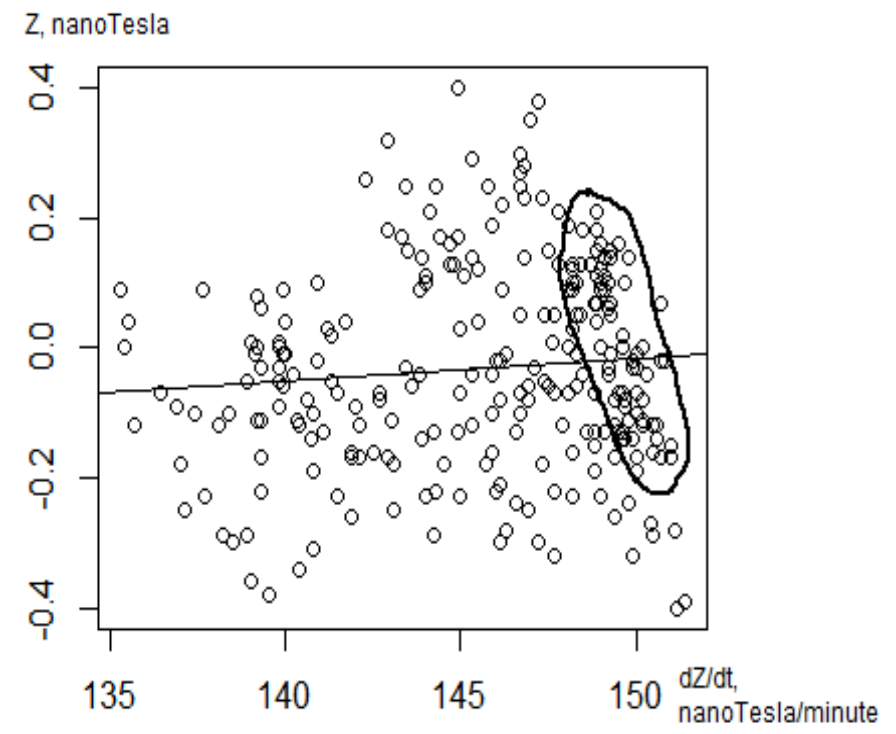

Fig. 3. Graphical representation of the cluster analysis results with $Z$ component, 22.07.2013

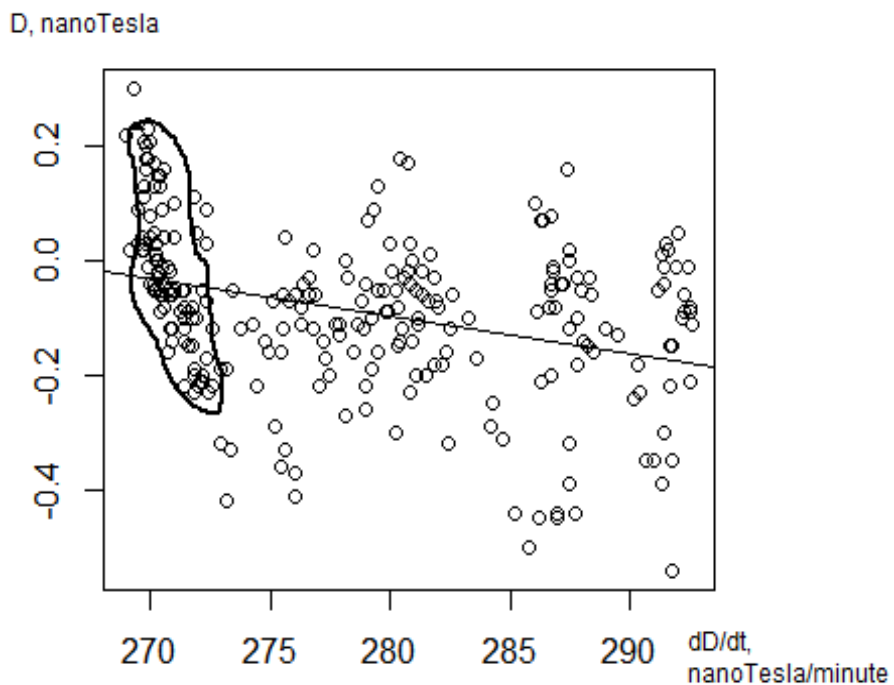

Fig. 4. Graphical representation of the cluster analysis results with $D$ component, 22.07.2013

Figure 2 shows that the clusters shape and size with $H$ component of $H=185 \div 195$ nanotesla indicate stability of the component properties in four-hour interval. We observe the tendency of $d H / d t$ reduction, i.e. $H$ "braking". $d H / d t$ variations are in the range of \pm 0.75 nanotesla per minute, which means they are the strongest. $Z$ component in the four-hour interval is changing less orderly. Figure 3 shows a small cluster at level $Z$ $=150$ nanotesla, which indicates the increased intensity of $Z$. In addition, $d Z / d t$ variations are in the range of \pm 0.2 nanotesla per minute, being significantly exceeded in scope and duration by $d H / d t$ variations. $D$ component cluster in Figure 4 is most clearly expressed at level $D=270 \div 275$ nanotesla. With that, $d D / d t$ variations are in the range of \pm 0.2 nanotesla per minute.

Thus, $d H / d t$ variations are the strongest, most continuous and occurring against the background of $H$ values corresponding to large geomagnetic storms.

The illustration of the cluster analysis carried out for studying the case of MRDP incorrect operation confirms our terms formulated in [21, 22]; simultaneous performance of these terms points to MDRP incorrect operation:

- Amplitudes of one or several geomagnetic components correspond to their values during intensive geomagnetic storms.

- Geomagnetic variations are in the range of \pm 0.5 nanotesla per minute and have, at least totally, one and a half hour time length.

\section{ANALYSIS OF GEOMAGNETIC VARIATIONS DURING GEOMAGNETIC STORMS}

Further we consider the results of the cluster analysis of the geomagnetic components according to the data of March 1, 2013. The geomagnetic field was calm on that day. There were no disturbances recorded in the operation of the power system facilities of the Republic of Khakassia. 
To perform clustering, there were selected statistical values $H, Z, D$ and calculated values of their variations $d H / d t, d Z / d t$ and $d D / d t$ in arbitrary time intervals of various lengths.

The results of the complex fuzzy clustering in four-hour interval from 00:00 to 04:00 are shown in Figures 5, 6, 7.

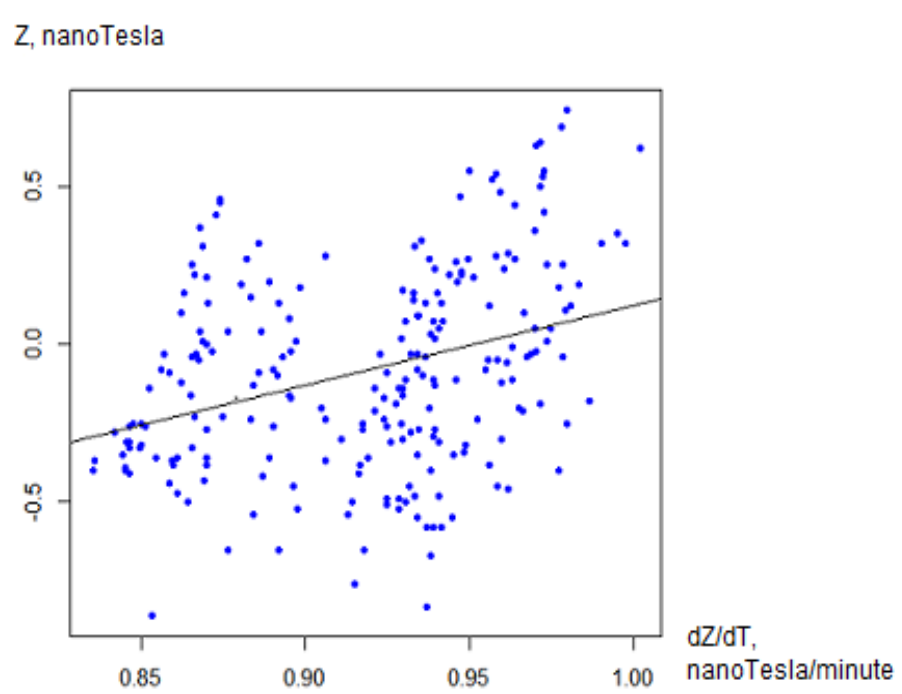

Fig. 5. Graphical representation of the cluster analysis results with $\mathrm{Z}$ component, 01.03.2013

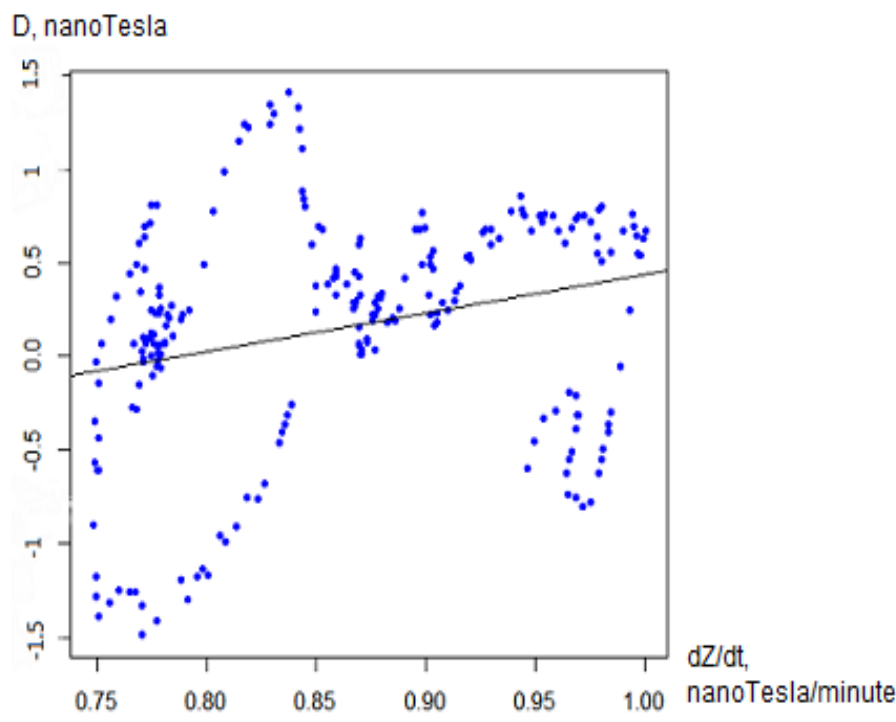

Fig. 6. Graphical representation of the cluster analysis results with $D$ component, 01.03.2013

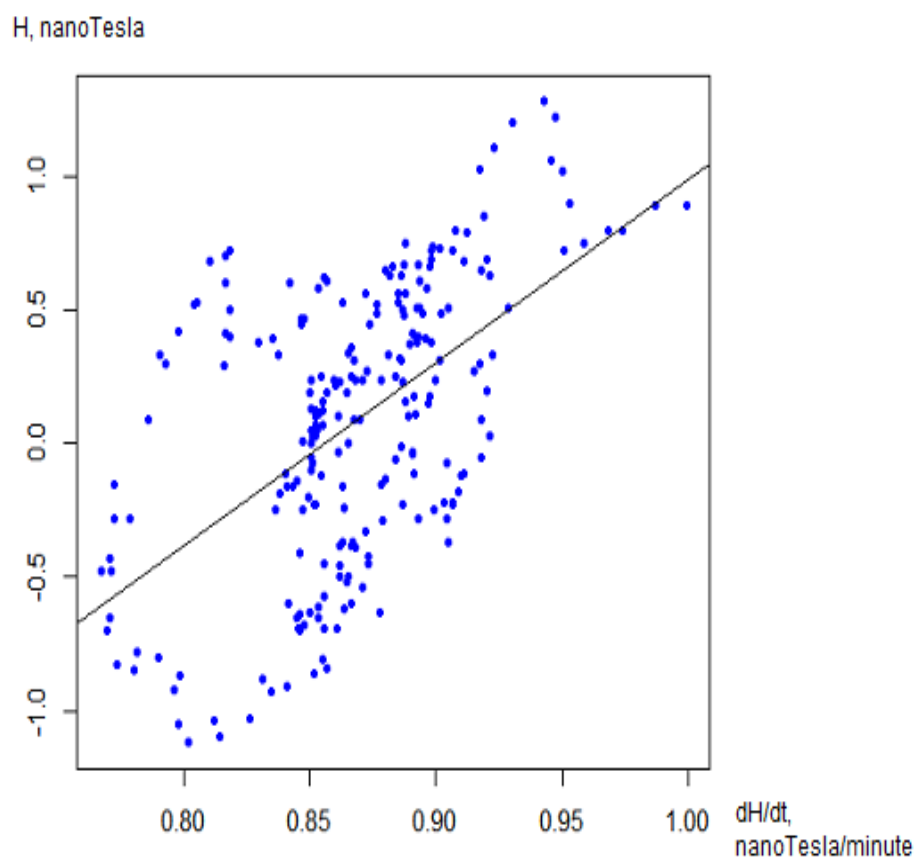

Fig. 7. Graphical representation of the cluster analysis results with $H$ component, 01.03.2013

According to Figures 5, 6, 7 there were no measurable clusters formed with any of the geomagnetic components, which means that the duration of intensive geomagnetic variations is small. $d H / d t, d Z / d t$ and $d D / d t$ values are in a wide range.

\section{CONCLUSION}

The purpose of the cluster analysis focused on the geomagnetic components during magnetic storms was to check the hypothesis about the dependence of the geomagnetic field components, the intensity of their variations and technological disturbances in the power system of the Republic of Khakassia caused by MRDP incorrect operation. The analysis of the cases concerning MDRP incorrect operation confirmed the high sensitivity of microprocessor devices of relay protection to the geoinduced current that is comparable to the setting current of MDRP relays. The geoinduced current values are established to be determined by the intensity of power and angle geomagnetic components and the speed of their change, which should be of a high value in a long time interval. Rate variations for geomagnetic power and angle components were determined with numerical differentiation of functions in a tabular form, with the construction of Lagrange interpolation polynomials of the second order.

The revealed regularities of MDRP incorrect operation at geomagnetic variations were taken into account in the estimation method for defining the influence of geomagnetic variations on MDRP operation. This method will be the basis of the mathematical model and software to predict the influence of geomagnetic variations on the reliability of the microprocessor relay protection devices. Such predicting will 
prevent the development of severe accidents and functional disturbances in electric power systems when geomagnetic surges are expected.

\section{REFERENCES}

[1] Sushko V.A., Kosykh D.A., "The geomagnetic storms. The threat to electrical power systems", News Of Electrical Engineering, 2013, - no. $1(79)$, pp. 26-30.

[2] John Kappenman, "Geomagnetic Storms and Their Impacts on the U.S. Power Grid", Meta-R-319, Metatech Corp., prepared for Oak Ridge National Laboratory, January 2010, pp. 1-14. 11. Geomagnetic storms can threaten electric power grid. American geophysical union, earth in space, 1997, vol. 9, no. 7, pp. 9-11.

[3] Pulkkinen A, "Large geomagnetically induced currents in the Finnish high-voltage power system", / A. Pulkkinen, A. Viljan // Reports 2. Finnish Meteorological Institute, Helsinki, 2000. - pp. 99.

[4] Avakian S.V., Voronin N.A., Dubarenko K.A., "The influence of magnetic storms on emergency power systems, automation and communication", Sientific-technical Bulletin of Saint-Petersburg state technical University, 2012, no. 154-2, pp. 253-266.

[5] Beland J., Small K., "Space Weather Effects on Power Transmission Systems", The Cases of Hydro-Québec and Transpower New Zealand Ltd // NATO Science Series II: Mathematics, Physics and Chemistry. 2005, no. 176. - pp. 287-299.

[6] Gershengorn A.I. "The influence of geomagnetic currents on electrical power systems", Power station, 1993, no.6, pp. 54-63.

[7] Vakhnina V.V., Rybalko T.A., "Effect of disturbances of space weather on the work of power supply systems", Volga Scientific Bulletin, 2015, no. 2(42), pp. 253-266.

[8] Skopintsev V.A., Markitanov D.V., "The influence of cosmic factors on the damage in electrical networks", Energetik, 2012, no. 10, pp. 8-11.

[9] Uspensky M.I., Smirnov S.O., "Major accidents in electric power systems: reasons and measures to counteract", Relay protection and automation, 2011, no.1(02), pp. 32-34.

[10] Vodianikov V.V., Gordienko G.I., Nechaev S.A., Sokolova O.I., Khomutov S.O., Iakovets A.F., "Induced currents in power lines according to geomagnetic variations", Geomagnetizm i aeronomiia Geomagnetism and Aeronomy, 2006, vol. 46, no. 6, pp. 853-858.

[11] Boteler D.H., "The effects of geomagnetic disturbances on electrical systems at the Earth's surface.", Advances in Space Research. - 1998. Vol. 22, No. 1. - pp. 17-27.

[12] Chistiakov G.N., Sigaev S.N., "Experimental study of the current in the neutral of the transformer in the period of geomagnetic storms", News of
Tomsk Polytechnic University, 2011, vol. 318, no. 4, 122-127. pp. 253266.

[13] Kretov D.A., "Calculation of heat losses in the tank of a power transformer under geomagnetic storms", Modern problems of science and education, 2012, no. 5, pp. 102-105.

[14] Barannik M.B., Danilin A.N., Sakharov Ia.A., Selivanov V.N., "Development of monitoring systems for induced Earth currents in the main lines of $330 \mathrm{kV}$ Kolenergo", Publishing house of the Kola science center, Russian Academy of Sciences "Electromagnetic compatibility and surge in high voltage networks". Apatity, 2004, pp. 7-18.

[15] Barannik M.B., Vilianen A., Danilin A.N., Katkalov Iu.V., Kolobov V.V., Prokopchuk P.I., Sakharov I.A., "Development of the measurement system jointaction currents in the North-West of Russia for EURISGIC project", Publishing house of the Kola science center, Russian Academy of Sciences "Electromagnetic compatibility and surge in high voltage networks". Apatity, 2011, pp. 120-125.

[16] Sivokon V.P., Serovetnikov A.C., Pisarev A.B., "Higher harmonics as an indicator of geomagnetically induced currents", Elektro - Electro, 2011, no. 3, pp.30-34.

[17] Gurevich V.I., "The problem of electromagnetic influence on microprocessor devices of relay protection. Part 1.”, Components and technologies, 2010, no. 2. - pp. 80-81.

[18] Gurevich V.I., "The problem of electromagnetic influence on microprocessor devices of relay protection. Part 2. ", Components and technologies, 2010, no. 3. - pp. 91-93.

[19] Gurevich V.I., "The problem of electromagnetic influence on microprocessor devices of relay protection. Part 3.", Components and technologies, 2010, no. 4. - pp. 91-96.

[20] Kucherov Iu.N., Gurevich Iu.E., "Problems of ensuring safety of consumers and electric power facilities in violation of operation of the power system", Energetic, 2007, no.8, pp. 8-12.

[21] "Data relating to the components of Earth's magnetic field", Institute of terrestrial magnetism, ionosphere and radio wave propagation named after N.V. Pushkov, access mode http://www.izmiran.ru/magnetism.

[22] Chistyakov G.N., Platonova E.V., Zarubina T.Yu., Panteleev V.I. "Influence of geomagnetic field perturbations on the reliability of the relay protection and automation devices", Electromagnetic compatibility technologies, 2017, no.2(61), pp. 25-36.

[23] Verzilova A.S., Voevoda A.E., Platonova E.V., "The methods of evaluating the impact of geomagnetic field variations on work of microprocessor-based relay protection", Proceedings of the VIII International Youth Scientific and Technical Conference "Power Utilizing the Eyes of Youth 2017”, Samara, 2017, Vol.1, pp.292-296. 